\title{
BMJ Open Towards a 'patient-centred' operationalisation of the new dynamic concept of health: a mixed methods study
}

\author{
M Huber, ${ }^{1} \mathrm{M}$ van Vliet, ${ }^{1,2} \mathrm{M}$ Giezenberg, ${ }^{3} \mathrm{~B}$ Winkens, ${ }^{4} \mathrm{Y}$ Heerkens, ${ }^{5}$ \\ P C Dagnelie, ${ }^{6} \mathrm{~J}$ A Knottnerus ${ }^{7}$
}

To cite: Huber M, van Vliet M, Giezenberg M, et al. Towards a 'patient-centred' operationalisation of the new dynamic concept of health: a mixed methods study. BMJ Open 2016;5:e010091. doi:10.1136/bmjopen-2015010091

\section{- Prepublication history} and additional material is available. To view please visit the journal (http://dx.doi.org/ 10.1136/bmjopen-2015010091).

Received 23 September 2015 Revised 30 November 2015 Accepted 1 December 2015

CrossMark

For numbered affiliations see end of article.

Correspondence to

Dr M Huber;

m.huber@louisbolk.nl

\section{ABSTRACT}

Objective: To evaluate among stakeholders the support for the new, dynamic concept of health, as published in 2011: 'Health as the ability to adapt and to self-manage', and to elaborate perceived indicators of health in order to make the concept measurable.

Design: A mixed methods study: a qualitative first step with interviews and focus groups, followed by a quantitative survey.

Participants: Representatives of seven healthcare stakeholder domains, for example, healthcare providers, patients with a chronic condition and policymakers. The qualitative study involved 140 stakeholders; the survey 1938 participants.

Results: The new concept was appreciated, as it addresses people as more than their illness and focuses on strengths rather than weaknesses. Caution is needed as the concept requires substantial personal input of which not everyone is capable. The qualitative study identified 556 health indicators, categorised into six dimensions: bodily functions, mental functions and perception, spiritual/existential dimension, quality of life, social and societal participation, and daily functioning, with 32 underlying aspects. The quantitative study showed all stakeholder groups considering bodily functions to represent health, whereas for other dimensions there were significant differences between groups. Patients considered all six dimensions almost equally important, thus preferring a broad concept of health, whereas physicians assessed health more narrowly and biomedically. In the qualitative study, $78 \%$ of respondents considered their health indicators to represent the concept.

Conclusions: To prevent confusion with health as 'absence of disease', we propose the use of the term 'positive health' for the broad perception of health with six dimensions, as preferred by patients. This broad perception deserves attention by healthcare providers as it may support shared decision-making in medical practice. For policymakers, the broad perception of 'positive health' is valuable as it bridges the gap between healthcare and the social domain, and by that it may demedicalise societal problems.

\section{Strengths and limitations of this study}

- The study is based on a large number of respondents, 140 for the qualitative part and 1938 for the quantitative part, spread over seven stakeholder domains of healthcare.

- Research questions were systematically studied by qualitative and quantitative research approaches, resulting in a valuable and rich amount of data that reveal the variation in perceptions regarding health among all main stakeholders involved.

- Response rates varied considerably between patients and, for example, physicians and policymakers, which impedes us from drawing firm conclusions.

- The choice for the elaboration of the new concept of health into the broad concept of 'positive health' connects to the prevailing policy trend of 'patient-centred care', and its implications are illustrated and supported by the results of our study.

- The study was restricted to the Netherlands and its generalisability to other, especially nonwestern populations, cannot be guaranteed without further research.

\section{INTRODUCTION}

In 2011, a new concept of health was introduced: 'Health as the ability to adapt and to self manage, in the face of social, physical and emotional challenges'. ${ }^{1}$ This new concept was proposed because the traditional WHO definition of health 'Health is a state of complete physical, mental and social well-being and not merely the absence of disease or infirmity'2 was considered no longer adequate. When first set out in 1948, the WHO definition was groundbreaking, as it encompassed physical, as well as mental and social aspects of health. However, at that time, morbidity mainly featured infectious diseases, while today, chronic diseases are 
much more prevalent. Moreover, the old definition described an unattainable utopian and static state, according to which almost everybody to some extent could be considered ill, and which unintentionally could enhance the risk of medicalisation. ${ }^{3-7}$ For example, with modern diagnostic techniques and steadily lowered cut-off points for laboratory values, borderline abnormal values can often be measured, also in the absence of disease, thus evoking unnecessary treatment just to be 'on the safe side'. Over time, the need for a dynamic description of health that highlights the human capacity for resilience and for coping with new situations-as we are repeatedly required to do in life-was increasingly being felt. ${ }^{8}$ Thus, the new 'general concept' of health, as provided above, was developed at an international invitational conference for experts held in the Netherlands in 2009. A concept was preferred over a definition that implies having set boundaries and precise, defined meanings. However, a general concept also needs further operationalisation into 'definitive concepts', for use in daily practice and for monitoring purposes. ${ }^{9}$ The research project described here is intended as a first step towards such operationalisation.

The study considered three research questions:

1. What do the various stakeholders consider to be positive and negative elements of the new general concept of health, and which elements should be specified in more detail?

2. What do different stakeholders consider to be indicators of health?

3. Do these indicators represent the new concept of health?

This approach allows the expressed indicators to be broad, which is in line with the discussions about a new broad concept of health in 2009, which finally condensed into the new dynamic concept. Question 3 was chosen to assess the relationship between the expressed indicators and the new concept.

\section{METHODS AND RESULTS-A TWO-STEP APPROACH Study design}

The study was performed using a mixed methods approach ${ }^{10}$ where the first step (A) was made with qualitative methodology in order to explore and generate data (different forms of interviews analysed with a manifest content analysis). The second step (B) was a verification phase that used quantitative methodology (a cross-sectional survey). The rationale for using a mixed methods approach was that two steps of data generation and verification were necessary to support the process of making the health concept more operational. ${ }^{5}$

\section{Participants}

Participants were stakeholders from seven main domains within healthcare: healthcare providers (physicians, nurses, physiotherapists), patients with a chronic condition, policymakers, insurers, public health professionals, citizens (as a representative reflection of society) and researchers from different professional backgrounds. In the recruitment of participants, the aim was to have a broad, representative spectrum of stakeholders in the Netherlands. The selection of people and organisations was based on the advice of healthcare opinion leaders and the authors' knowledge about the field.

\section{Ethical considerations}

This study is exempt from ethical approval in the Netherlands. The participants from the interview and survey study were informed of the study's purpose, mode of participation and confidentiality. Participation was entirely voluntary, and data were handled confidentially.

\section{The first explorative step: a qualitative approach} Methods-A

\section{Participants and data collection}

During this explorative phase, 37 qualitative (semistructured) interviews and 13 focus group sessions were held, involving a total of 140 people from seven stakeholder domains (see table 1). During the meetings, first a preparatory introduction to the WHO definition and the new concept of health was provided, and subsequently the three research questions were posed to guide the interviews and focus group sessions. The questions framed the interviews, where the interviewer encouraged participants to elaborate, specify and discuss their opinions.

Individual and minigroup interviews (two or three persons) were conducted by the first author face to face, except from two interviews by phone call. Focus group

Table 1 Numbers of interviews and group distribution

\begin{tabular}{llcl}
\hline & $\begin{array}{l}\text { Interviews } \\
\text { (N) }\end{array}$ & $\begin{array}{l}\text { Participants } \\
(\mathbf{N})\end{array}$ & Stakeholder groups \\
\hline $\begin{array}{l}\text { Individual interviews } \\
\text { Minigroup interviews (two or }\end{array}$ & 70 & 30 & $\begin{array}{l}\text { Physicians, physiotherapists, policymakers, insurers, public } \\
\text { health professionals, researchers } \\
\text { Physicians, policymakers, insurers, public health } \\
\text { professionals }\end{array}$ \\
$\begin{array}{l}\text { Focus group interviews } \\
\text { Total }\end{array}$ & 13 & 15 & $\begin{array}{l}\text { Nurses, patients, citizens, policymakers, public health } \\
\text { professionals }\end{array}$ \\
\hline
\end{tabular}


meetings were held at a central location in the Netherlands and were successively chaired by one of the first three authors. The meetings were audio recorded, transcribed and summarised, and sent back to the interviewees for approval. Interviews and focus groups went on beyond the moment that saturation was reached, in order to give as broad and representative a spectrum of stakeholders as possible the opportunity to express their opinion.

\section{Data analysis}

Meaning units (sentences, paragraphs) related to research question 1 (What do respondents consider to be positive and negative elements of the new concept, and which specifications are needed?) were identified and systematically coded on the basis of their manifest content (what was said) and thereafter sorted on the basis of similarities. Meaning units related to research question 2 (What are according to you indicators of health?) were coded and sorted in line with the step above. ${ }^{11}$ On the basis of their mutual content, categories were identified and category names were formulated. Literature on existing classifications was used to guide the identification and naming of the categories. ${ }^{12-17}$

This process resulted in an initial choice of categories. In a subsequent step, two experienced researchers from the research institute NIVEL, both independently from each other, took the proposed categories into consideration and categorised all meaning units over these proposed categories or named new ones. The final step involved consensus meetings with all researchers involved. All differences of opinion were discussed, and the main categories, the dimensions, and related aspects were agreed on by consensus. By doing so, we aimed to increase reliability. ${ }^{11}$

Question 3 (Do your indicators of health represent the new concept?) comprised fixed answers of yes or no; therefore, these responses were quantified as percentages.

\section{Results-A}

Positive elements of the new health concept as derived by research question 1 are depicted in box 1 .

Furthermore, analyses of research question 1 elicited several negative elements that are depicted in box 2.

\section{Box 1 Positive elements of the new health concept}

- It emphasises that a person is more than his/her illness and still has a large potential for being healthy

- The focus is on a person's strengths rather than his/her weakness

It refers to self-management

- It refers to individual responsibility

- Health is described as being dynamic rather than a static state

- It may make the relationship between patient and healthcare provider more balanced

\section{Box 2 Negative elements of the new health concept}

- The concept is too broad and about life as a whole, instead of only about health

- It denies that health is mainly the absence of disease

- It requires substantial personal input-is everybody capable of this?

- It entails personal responsibility-does everybody want this?

- It seems to ignore the importance and impact of real illness

- It brings the risk that people will consult a doctor too late

- It can be an excuse for policymakers, as if people just need to adapt to existing, poor living conditions

In respect of research question 1, respondents advised several specifications concerning the new concept (see box 3).

Research question 2 (What are to you indicators of health?) yielded 556 statements about health indicators, which were categorised into six dimensions, covering 32 aspects (see table 2).

This study was about indicators rather than determinants of health. Yet, many patients stated that the indicators they mentioned were also perceived by them as determinants of health.

Answers to research question 3 (Do your indicators of health represent the new concept?) yielded a score of $78 \%$ positive, $12 \%$ negative and $10 \%$ hesitant opinions. Lists of indicators differed considerably between stakeholders.

\section{The second step: a quantitative approach}

\section{Methods-B}

\section{The survey}

The results of the qualitative phase were quantitatively tested in an anonymous, structured online questionnaire including all stakeholder groups (see online supplementary file 1 ).

Participants were asked to respond from the perspective of their respective roles in healthcare, where applicable. The survey included questions on demographic and other characteristics (eg, if participants had a chronic illness).

Following an introduction about the existing WHO definition and the new concept of health, respondents

Box 3 Specifications advised by respondents for the new health concept

- Emphasise that this concept of health is different from health being the 'absence of disease'

- Health is a domain that can be developed, publicly and privately, in addition to the domain of the medical treatment of disease

- Actions to enhance health should take into account people's capabilities and motivations to act

- Consider referring to the concept as 'positive health'

Visualise it, for example, in a web diagram 


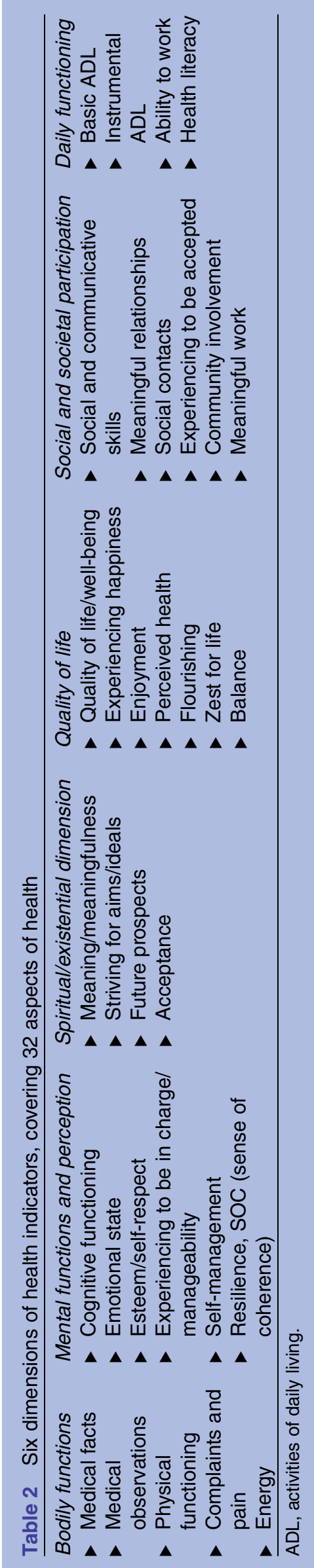

were asked for their positive and/or negative opinions about this new concept. The questionnaire presented the main positive and negative opinions, as expressed in the interviews. Respondents could agree or disagree with an unrestricted number of the opinions. They were also invited to make additional positive or negative comments.

Thirty-two statements covering all health domains that were derived from the interviews were presented, and respondents were asked if they considered the statements to apply to 'health'. Each statement generally corresponded to a specific aspect of health. Respondents were asked to assign a score between 1 ('completely unimportant') and 9 ('highly important') to each of the statements. There was also a 'Don't know' option. The survey was piloted among several members from each stakeholder domain before final distribution.

Question 3 (Do your indicators of health represent the new concept?) was not included in the online questionnaire as this question did not fit well in the questionnaire and it was expected not to yield reliable answers. In the qualitative phase, question 3 was connected to each respondent's own list of health indicators, whereas in the survey a fixed set of indicators was presented to the respondents.

\section{Participants and data collection}

The survey was distributed among adult representatives from all seven stakeholder groups. The aim was to obtain as large and representative a sample as possible from the different target groups. Physicians and physiotherapists were approached via the official panels of their professional associations. These panels consist of members who voluntarily have subscribed to a list of people who are occasionally invited for online surveys. For physicians, it is representative of age, gender and specialisation. All members of both panels were invited to complete the survey questionnaire and thereby no stratification took place.

Citizens were sampled from validated and representative panels of the research agency Flycatcher. This sample was stratified for age, gender, level of education and region. A select sample of chronically ill people was drawn from this same validated panel to represent patients. Additional patients were recruited by a groupmail to all members of eight main patient organisations.

All physicians, physiotherapists, patients and citizens were invited via an email containing a link to the online survey. After 4-14 days, reminders were sent.

No panels were available for other stakeholder groups, and therefore participants were sampled by snowball sampling. Participants were approached through networks within their stakeholder domains, including the Dutch nursing association, policymakers, insurers, public health professionals and researchers. They were also invited to complete the survey questionnaire via an email containing a link to the online survey. Additionally, announcements with a link to the 
questionnaire were included in newsletters, posted on certain websites and distributed via social media.

Data collection took place during October to November 2012. No empty fields were allowed during the completion of the questionnaire to avoid missing data.

\section{Data analysis}

General characteristics of responders and the responses regarding the positive and negative aspects of the new health concept are presented by mean $\pm \mathrm{SD}$ for numerical variables and number $(\mathrm{N})$ and/or percentages for categorical variables. In addition, mean scores for each health aspect were calculated and used to construct composite scores reflecting their importance. Subsequently, general linear models (GLM) were fitted, both uncontrolled and controlled, for age, gender, level of education and chronic disease to test for differences between stakeholder groups. GLM models were also fitted, both uncontrolled and controlled, for age, gender and chronic disease for subgroup analyses among the group of healthcare providers. Data were analysed using SPSS V.21.0 (IBM, New York, USA). A two-sided $\mathrm{p}$ Value $\leq 0.05$ was considered statistically significant.

\section{Results-B}

\section{Response rate and demographics}

In total, 1938 respondents from seven stakeholder groups completed the survey. Different response rates were obtained from the panels. The response rates were $30 \%$ for physicians $(\mathrm{n}=317), 35 \%$ for physiotherapists $(\mathrm{n}=216), 71 \%$ for patients $(\mathrm{n}=455)$, and $62 \%$ for citizens $(n=430)$. Further, 170 responders from a convenience sample among eight patient associations were included in the group of patients, resulting in 575 patients with diverse chronic diseases. Response rates for other stakeholder groups cannot be provided, as it is unknown how many individuals in total were reached.

The demographic characteristics of the respondents are outlined in table 3. More than half of all respondents (55.3\%, $\mathrm{n}=1071$ ) had experienced at least one chronic condition in his/her life. Cardiovascular disease $(15.7 \%, \mathrm{n}=305)$, neck and/or backache $(13.6 \%, \mathrm{n}=264)$, diabetes $(11.3 \%, \mathrm{n}=219)$, chronic joint problems $(10.7 \%, \mathrm{n}=207)$, respiratory disease $(10.3 \%, \mathrm{n}=200)$, and cancer $(5.7 \%, \mathrm{n}=110)$ were the most common chronic conditions (per respondent more than one answer possible).

\section{Positive and negative aspects of the new concept}

The 1938 respondents scored 4514 positive and 3443 negative aspects, plus an additional four positive and five negative aspects in the category 'other' (see tables 4 and 5).

\section{Mean scores and composite scores per health aspect}

The mean scores for each of the 32 statements varied from 6.58 to 7.80 on a nine-point scale with SDs ranging from 1.13 to 1.99 (see online supplementary file 2). Composite scores based on the mean of corresponding health-aspect subscores were calculated and checked for internal consistency by determining Cronbach's $\alpha$. This showed strong correlations between the aspects scores within the dimensions and thereby supported the selection of each set of aspects to represent the dimensions.

\section{Importance of health dimensions as perceived by stakeholders}

\section{General}

Mean composite scores about the importance of each dimension as being part of 'health' are represented on a nine-point scale in figure 1, per stakeholder group.

This figure shows marked variation in mean composite scores between stakeholder groups for all health dimensions, except from bodily functions. Uncontrolled GLM confirms no significant difference in mean composite scores for bodily functions between stakeholder groups ( $p=0.583$ ), in contrast to significant differences between stakeholder groups for all other dimensions (all $p$ values $\leq 0.001)$. Corrected GLM showed that these differences were still significant after controlling for age, gender, level of education (academic vs non-academic), and having (had) a chronic disease (yes or no) ( $p=0.628$ for bodily functions, $\mathrm{p}=0.040$ for daily functioning, and $\mathrm{p}<0.001$ for all other dimensions).

2. Patients and healthcare providers (see online supplementary file 3 )

Figure 2 shows the mean composite scores on the importance assigned to each dimension as part of 'health' by various healthcare providers and patients.

Among the healthcare providers, the mean composite scores of nurses were generally the highest and most congruent with those of patients $(p \geq 0.105)$, except for daily functioning $(p=0.002)$. Uncontrolled GLM demonstrated that all mean composite scores showed significant differences between patients and physicians (all $\mathrm{p}$ values $\leq 0.042$ ). After controlling for age, gender and chronic disease, all differences in dimension composite scores between physicians and patients remained statistically significant (all $\mathrm{p}$ values $\leq 0.034$ ), except for the dimension bodily functions $(\mathrm{p}=0.136)$.

3. Healthcare providers according to whether they have experienced a chronic disease (see online supplementary file 4)

Uncontrolled GLM demonstrated that mean composite scores for physicians who had experienced a chronic disease were significantly higher for the spiritual/existential dimension, social and societal participation and daily functioning (all $\mathrm{p}$ values $\leq 0.050$ ), compared to physicians without experience of chronic disease. Uncontrolled GLM showed no differences between nurses and physiotherapists with or without experience of chronic disease, except for the spiritual/existential dimension, which was significantly higher among nurses with a chronic disease $(p=0.042)$. Controlling for age and gender (physicians and physiotherapists) and age 


\begin{tabular}{|c|c|c|c|c|c|c|c|c|}
\hline & Total & $\begin{array}{l}\text { Healthcare } \\
\text { providers }\end{array}$ & Patients & Citizens & Policymakers & Insurers & $\begin{array}{l}\text { Public health } \\
\text { actors }\end{array}$ & Researchers \\
\hline $\mathrm{N}$ & 1938 & 643 & 575 & 430 & 80 & 15 & 89 & 106 \\
\hline Per cent & 100 & 33.2 & 29.7 & 22.2 & 4.1 & 0.8 & 4.6 & 5.5 \\
\hline \multicolumn{9}{|l|}{ Gender (\%) } \\
\hline Male & 42.5 & 43.3 & 41.2 & 51.2 & 31.3 & 73.3 & 19.1 & 33.0 \\
\hline Female & 57.5 & 56.6 & 58.8 & 48.8 & 68.8 & 26.7 & 80.9 & 67.0 \\
\hline Age (years $\pm S D$ ) & $51.6 \pm 13.4$ & $50.3 \pm 9.5$ & 56.6 & 52.5 & $44.6 \pm 10.9$ & 42.6 & $45.1 \pm 11.5$ & $40.6 \pm 11.3$ \\
\hline \multicolumn{9}{|l|}{ Type of employment (\%) } \\
\hline Independent & 16.9 & 41.8 & 5.6 & 5.3 & 0 & 0 & 1.1 & 2.8 \\
\hline Salaried employee & 50.0 & 52.9 & 28.3 & 44.7 & 98.8 & 100.0 & 95.5 & 89.6 \\
\hline Flexible/on call & 2.0 & 0.6 & 2.4 & 4.9 & 0 & 0 & 0 & 0 \\
\hline Retired & 14.3 & 1.6 & 29.4 & 22.6 & 0 & 0 & 1.1 & 0.9 \\
\hline $\begin{array}{l}\text { Unable to work/disability } \\
\text { (full or partial) }\end{array}$ & 5.2 & 0 & 17 & 0.2 & 0 & 0 & 0 & 0.9 \\
\hline Social security benefit & 0.6 & 0 & 1.4 & 0.5 & 1.3 & 0 & 0 & 0 \\
\hline No work/other & 9.1 & 0.6 & 14.4 & 20.7 & 0 & 0 & 1.1 & 0 \\
\hline Combination of jobs & 1.9 & 2.5 & 1.4 & 1.2 & 0 & 0 & 1.1 & 5.7 \\
\hline \multicolumn{9}{|l|}{ Highest level of education (\%) } \\
\hline Elementary or high school & 6.2 & 0 & 10.6 & 13.3 & 2.5 & 0 & 0 & 0 \\
\hline Junior vocational training & 4.6 & 0 & 9.9 & 7.7 & 0 & 0 & 0 & 0 \\
\hline $\begin{array}{l}\text { Secondary vocational } \\
\text { training }\end{array}$ & 23.2 & 4.2 & 40.7 & 42.6 & 0 & 0 & 4.5 & 0.9 \\
\hline Professional training & 29.8 & 46.5 & 28.2 & 21.9 & 5 & 26.7 & 13.5 & 1.9 \\
\hline University degree & 36.2 & 49.3 & 10.6 & 14.7 & 92.5 & 73.3 & 82.0 & 97.2 \\
\hline \multicolumn{9}{|c|}{ Personal experienced disease(s) (\%) } \\
\hline Yes & 55.3 & 33.3 & 100 & 48.1 & 26.3 & 20.0 & 29.2 & 24.5 \\
\hline No & 44.7 & 66.7 & 0 & 51.9 & 73.8 & 80.0 & 70.8 & 75.5 \\
\hline
\end{tabular}


Table 4 Positive aspects of the new health concept according to respondents

\begin{tabular}{lll}
\hline I feel positive about the new concept:* & N & per cent† \\
\hline It emphasises that a person is more than his/her illness & 967 & 943 \\
It emphasises people's strengths rather than their weaknesses & 876 & 862 \\
Health is seen as a dynamic rather than a static state & 581 \\
It emphasises self-management & 285 \\
It focuses on individual responsibility & 48.7 \\
It makes the patient more equal to the practitioner & 12 \\
Other (summarised): & 10 \\
It focuses attention on the path towards health & 8 \\
This is broad and feasible & 6 \\
It stresses that you can still feel healthy despite a chronic disease & 83 \\
It emphasises adaptability & 44.5 \\
Other/do not know/nothing negative & 30.0 \\
*Respondents were free to give more than one answer. & 14.7 \\
†Percentage of the total population (N=1938). & 0.6 \\
\hline
\end{tabular}

(nurses) by GLM revealed that physicians with a chronic disease considered the spiritual/existential dimension $(\mathrm{p}=0.007)$ and the dimension social and societal participation $(\mathrm{p}=0.002)$ significantly more important than physicians without a chronic disease.

Overall GLM analysis revealed that having a chronic disease, for the whole research population, was independently related to lower scores for the dimension bodily functions and higher scores for the spiritual/ existential dimension (see online supplementary file 5).

\section{DISCUSSION}

In this exploratory study, with qualitative and quantitative elements, we evaluated the support for the new dynamic concept of health as 'the ability to adapt and to self-manage, in the face of social, physical and emotional challenges' and elaborated indicators of health, perceived to connect to the concept, in order to make the concept measurable and by that take a first step towards operationalisation. We could have chosen existing questionnaires on 'ability to cope', 'resilience' and 'selfmanagement' as a starting point, to make the concept measurable, but preferred an open enquiry for indicators of health. This approach is connected to the broad and open discussions which led in 2009 to the new dynamic concept of health and enabled us to integrate the perceptions of all stakeholders in the elaboration of the concept.

The concept received considerable support from all stakeholder groups. What most respondents generally appreciated about the new concept was that a person is described as more than his illness, and that the focus is on a person's strength rather than his weakness. A point of attention was the notion that the concept requires substantial personal input, something not everyone would be capable of.

A broad range of health indicators was mentioned, which we categorised into six dimensions: bodily functions, mental functions and perception, spiritual/existential dimension, quality of life, social and societal participation, and daily functioning, with underlying

Table 5 Negative aspects of the new health concept according to respondents

\begin{tabular}{lll}
\hline I feel negative about the new concept: & per cent $\mathbf{~}$ \\
\hline It asks a lot of people, is everyone capable of self-management? & 810 & 41.8 \\
This description seems to make actual disease unimportant & 604 & 31.2 \\
This is too broad, it is about life and not about health & 599 & 30.9 \\
For me, health is primarily the absence of disease & 426 & 22.0 \\
It asks a lot of people, does everyone want to take responsibility? & 426 \\
Should anyone simply adjust to poor living conditions? & 337 \\
It could keep someone from going to the doctor in time & 241 \\
Other (summarised) & 32 \\
It is vague and unclear & 19 \\
Not everything can be attributed to individual behaviour & 16 \\
Too little consideration of the influence of the social environment & 13 \\
Danger that victims will be blamed & 10 \\
Old definition is fine & 95 \\
Other/don't know/nothing positive. & 17.4 \\
\hline
\end{tabular}

${ }^{*}$ Respondents were free to give more than one answer.

†Percentage of the total population $(\mathrm{N}=1938)$. 
Mean score per dimension for different stakeholder groups

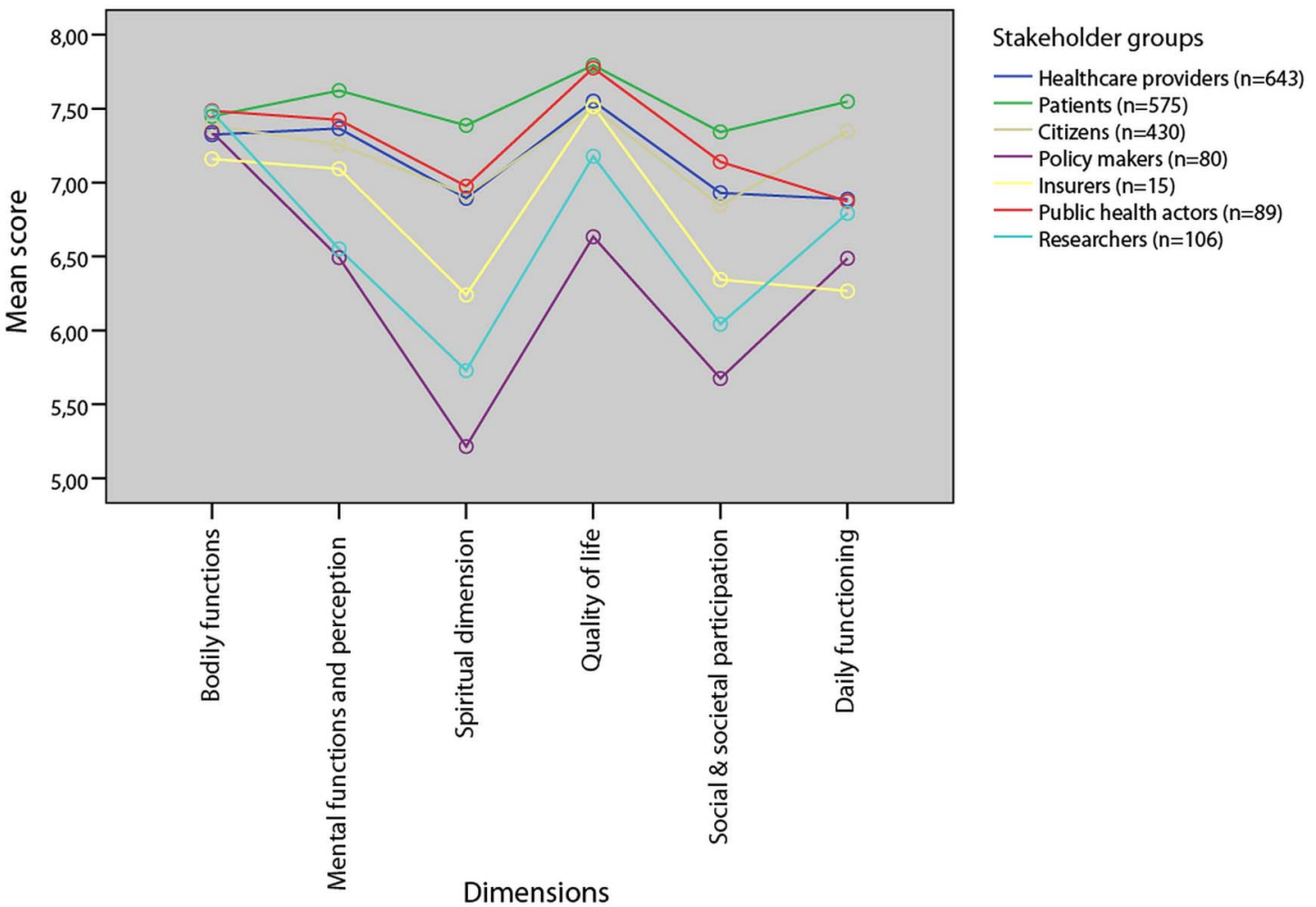

Figure 1 Mean scores per stakeholder group on a nine-point scale, indicating the importance assigned by respondents to a dimension as being part of 'health'.

aspects. Seventy-eight per cent of respondents in the qualitative study felt that their indicators fitted in with the new concept, thus amply supporting a match between the concept and the indicators of individual stakeholders. Different stakeholder groups mentioned different types of health indicators, yet many of the stakeholders found their indicators to reflect the concept.

The survey confirmed the support for the concept and the positive and negative elements connected to the concept. Concerning the different health indicators, the survey showed that all stakeholder groups considered bodily functions to represent health, whereas judgements about the other dimensions differed significantly between groups. Patients considered all six dimensions as almost equally important, thus preferring a broad concept of health, whereas policymakers as well as healthcare providers (and among the latter especially physicians) assessed health in a more narrow and biomedical way.

A strength of the study is the evaluation of the new concept of health among a broad representation of stakeholders in healthcare and the exploration of health indicators among these stakeholders, resulting in a $78 \%$ match between the expressed indicators and the concept during the qualitative phase. The exploration of health indicators followed a bottom-up inductive approach, resulting in a categorisation of six main dimensions and 32 aspects of health, with unexpected but clear differences in perceptions as an interesting result of the survey. Another strength is the large number of survey respondents.

A limitation of the study is that question 3 (Do your indicators of health represent the new concept?) was not included in the online questionnaire. In this questionnaire, all 32 indicators were presented to the respondents and it would have required a different way of questioning to find the match between the concept and the indicators. Therefore, the answer to question 3 was solely based on the results of the qualitative phase. Further research to study the relation between the health indicators put forward by stakeholders and the new health concept, as proposed by the invitational conference of 2009, is recommended.

Another limitation is that response rates varied in the quantitative phase, for patients being $71 \%$, for citizens $62 \%$, whereas the response rate for physicians was only $30 \%$. This lack of motivation of physicians, to consider the content of the concept of 'health', seems concordant with the main outcome of our study, namely the apparent differences in perceptions of health between physicians and patients, where health interests are concerned. Furthermore, a potential for response bias exists, because people in favour of the newly posed health concept might have been more willing to complete the survey. However, if this would be the case, it seems plausible that differences between patients and 
Mean score per dimension for patients and healthcare providers

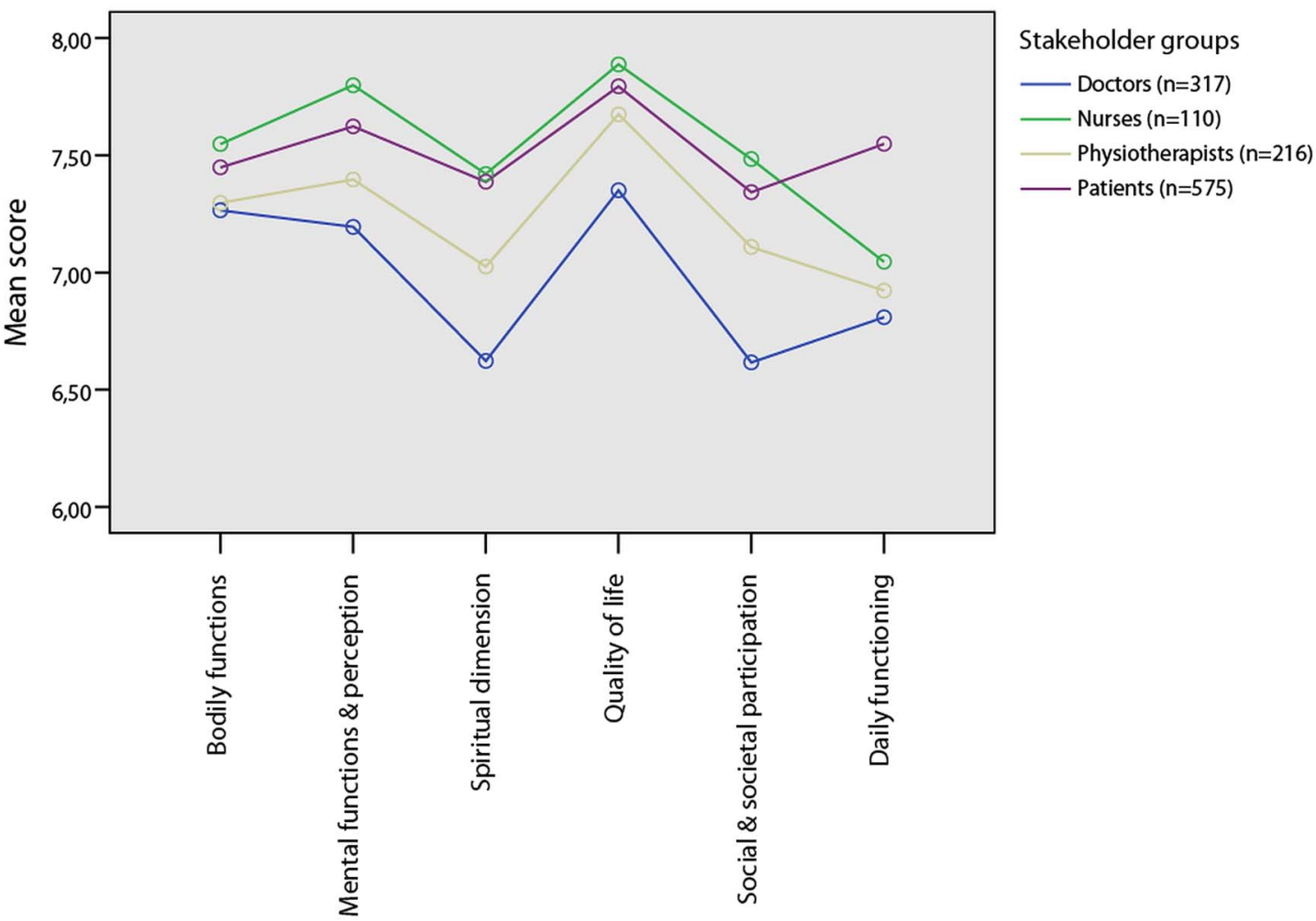

Dimensions

Figure 2 Mean scores per healthcare provider group and patients on a nine-point scale, indicating the importance assigned by respondents to a dimension as being part of 'health'.

other stakeholder groups would be even larger. Owing to practical limitations, it was not feasible to generate representative and stratified samples for participation in this study, except from physicians, physiotherapists, patients and citizens. Instead, the relatively uncontrolled method of snowball sampling was used for other stakeholder groups. Therefore, results should be cautiously

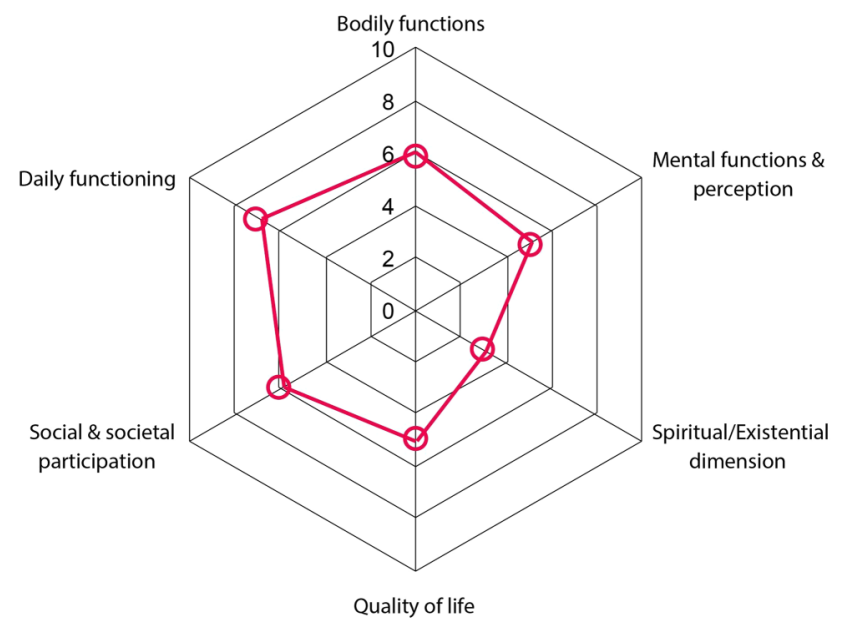

Figure 3 The six dimensions on a subjective scale, visualised for practical use, indicating a fictional estimation of a person's state of 'positive health'. interpreted and more research is needed to generalise the results to the whole population. Finally, the study was conducted in the Netherlands and its generalisability to other, especially non-western, populations will need to be studied too.

The existing literature about health indicators and patient reported outcome measures was studied during the categorisation process of the statements in the qualitative phase. This showed that the statements obtained in the present study covered a broader area of life than most generic measures of perceived health and health-related quality of life. The fact that we found such broadness might be considered a weakness, as we cannot connect the results to an existing measurement instrument. However, it might be considered a strength that our results have a broad empirical basis. We found most congruence of our findings with the dimensions and aspects reported in a study by Stewart $e t a l^{16}$ on the quality of life of dying persons, and as described by Willemstein $e t a l^{17}$ for outcome measures in the care sector. We compared our findings to the International Classification of Functioning, Disability and Health (ICF) ${ }^{18}$ the WHO's present terminology on health, functioning and health-related domains with multidimensional concepts, but were not able to categorise or code many of the statements using the ICF. One important reason for this is that the ICF lacks a classification of 
personal factors, and many of our aspects seemed to best suit this category. The first and fifth authors, who are ICF-specialists, elaborated together the 32 'aspects' of positive health, linking them to the most appropriate ICF categories, using the linking rules of Cieza. ${ }^{19}$ Of the 32 aspects, 18 were coded as personal factors. We concluded that the personal factors we uncovered in our study could be used as input for attempts to formulate a list of ICF Personal Factors.

Physicians assessed health significantly more narrowly (main emphasis on bodily functions and quality of life) than did patients, whereas for physicians who had experienced a chronic disease, the spiritual/existential dimension and social and societal participation became more important.

Overall, having a chronic disease was itself independently related to a decrease in the value placed on bodily functions and an increase in the value awarded to the spiritual/existential dimension.

This phenomenon-a change in perception after experiencing a major life event such as facing a chronic disease-connects with what is described as a 'response shift'; a change in experienced quality of life and health-related quality of life when facing a serious illness. This has been described in other studies, both in general and for specific diseases. ${ }^{20-23}$

The discrepancy between the broader perception of health of patients and the mainly narrower perception of health held by other stakeholders requires attention, if the prevailing policy trend of 'patient-centred care' is to be taken seriously. To emphasise the difference to the narrow interpretation of health as 'the absence of disease', we propose for the broad perception of health the concept of 'positive health' and to illustrate this with the web diagram shown in figure 3 .

Patients' broad perception of health, or 'positive health', should receive attention, as this may prevent misunderstandings and improve communication in medical practice, especially when 'shared decision making' is also practised and the question is posed on which aspect of the web diagram the patient has the wish to improve his/her situation. This could very well be a different area than the medical domain and another professional than a physician might first be needed. This approach might empower patients and by that connect to the new concept of health.

Future research should explore whether actions or interventions undertaken by patients on aspects of their choice on the different dimensions result in improvements in the 'ability to cope', 'resilience' and 'selfmanagement', as well as in physical and mental health, in functioning in the different dimensions, and/or in health-related quality of life. Future research should develop and validate a measurement instrument for the various dimensions and aspects of 'positive health' and e-health advices could be linked to the different dimensions, in case individuals want to act and improve their situation on a certain aspect.
We propose the concept of 'positive health' and the web diagram as a first 'definitive concept' as referred to by Blumer, ${ }^{9}$ elaborated from 'Health as the ability to adapt and self manage in the face of social, physical, and emotional challenges'.

\section{Author affiliations}

${ }^{1}$ Department of Healthcare and Nutrition, Louis Bolk Institute, Driebergen, The Netherlands

${ }^{2}$ Department of Health Sciences, Mid Sweden University, Sundsvall, Sweden

${ }^{3}$ Policy-Analysis and Entrepreneurship in Health and Life Sciences at VU University Amsterdam, Amsterdam, The Netherlands

${ }^{4}$ Department of Methodology and Statistics, Faculty of Health, Medicine and Life Sciences, Maastricht University, Maastricht, The Netherlands

${ }^{5}$ Dutch Institute of Allied Health Care, Amersfoort \& HAN University of Applied Sciences, Research Group Occupation \& Health, Nijmegen, The Netherlands

${ }^{6}$ Department of Epidemiology, Faculty of Health, Medicine and Life Sciences, Maastricht University, Maastricht, The Netherlands

${ }^{7}$ Department of General Practice \& Scientific Council of Government Policy,

Maastricht University, The Hague, The Netherlands

Acknowledgements The authors thank all participants from the different stakeholder groups for their input in the interviews and focus groups, and the larger groups of stakeholders for contributing to the questionnaire. They also thank the researchers of the NIVEL Institute for their input in the process of categorising the indicators of health.

Contributors $\mathrm{MH}$ conceptualised and designed the study in cooperation with $\mathrm{MvV}$ and $\mathrm{MH}$ was involved as project leader and researcher in the whole study. MH performed interviews, MH, MvV and MG performed focus groups and analysed the qualitative results. MH and MvV designed the questionnaire, $\mathrm{MH}$ recruited participants and MvV statistically analysed the outcomes. BW supervised statistics, YH and MH related the Positive health concept and ICF, PCD and JAK supervised the study. MH drafted the manuscript with input from MvV on methodology, statistics, tables and figures, from YH on ICF. All co-authors contributed to the discussion and critically revised the manuscript. JAK is guarantor.

Funding The study was funded by the Netherlands Organisation for Health Research and Development (grant number 20005095404) and by the Optimix Foundation.

\section{Competing interests None declared}

Provenance and peer review Not commissioned; externally peer reviewed.

Data sharing statement No additional data are available.

Open Access This is an Open Access article distributed in accordance with the Creative Commons Attribution Non Commercial (CC BY-NC 4.0) license, which permits others to distribute, remix, adapt, build upon this work noncommercially, and license their derivative works on different terms, provided the original work is properly cited and the use is non-commercial. See: http:// creativecommons.org/licenses/by-nc/4.0/

\section{REFERENCES}

1. Huber M, Knottnerus JA, Green L, et al. How should we define health? BMJ 2011;343:d4163.

2. WHO. Constitution of the World Health Organization. 2006. http:// www.who.int/governance/eb/who constitution en.pdf

3. Saracci R. The World Health Organisation needs to reconsider its definition of health. BMJ 1997;314:1409-10.

4. Bircher J. Towards a dynamic definition of health and disease. Med Health Care Philos 2005;8:335-41.

5. Wylie CM. The definition and measurement of health and disease. Public Health Rep 1970;85:100-4.

6. Smith R. The end of disease and the beginning of health [WWW document]. 2008. http://blogs.bmj.com.proxy.library.uu.nl/bmj/2008/ 07/08/richard-smith-the-end-of-disease-and-the-beginning-of-health/

7. Fitzgerald FT. The tyranny of health. N Engl J Med 1994;331:196-8.

8. Jadad AR, O'Grady L. How should health be defined? BMJ 2008;337:a2900. 
9. Blumer H. Symbolic interactionism: perspective and method. Prentice Hall, 1969.

10. Creswell JW. Research design: qualitative, quantitative, and mixed methods approaches. Sage, 2009.

11. Graneheim UH, Lundman B. Qualitative content analysis in nursing research: concepts, procedures and measures to achieve trustworthiness. Nurse Educ Today 2004:24:105-12.

12. Wolcott HF. Transforming qualitative data: description, analysis, and interpretation. Thousand Oaks: Sage, 1994.

13. [No authors listed]. Development of the World Health Organization WHOQOL-BREF quality of life assessment. The WHOQOL Group. Psychol Med 1998;28:551-8.

14. Oberhauser C, Escorpizo R, Boonen A, et al. A statistical validation of the brief international classification of functioning, disability and health core set for osteoarthritis based on a large international sample of patients with osteoarthritis. Arthritis Care Res (Hoboken) 2013;65:177-86.

15. Scholten JHG, van Weel C. Functional status assessment in family practice-the Dartmouth COOP functional health assessment charts/Wonca. Lelystad: MediTekst, 1992.

16. Stewart A, Teno J, Patrick DL, et al. The concept of quality of life of dying persons in the context of health care. J Pain Symptom Manage 1999;17:93-108.
17. Willemstein $M$, van den Berg $B$, Vos $R$, et al. Verkenning effectmaat voor de care sector, Rapportage onderzoeksproject (in Dutch). In opdracht van CVZ, EMGO/Maastricht University, 2009. www.emgo. $\mathrm{nl} / \mathrm{files} / 60$

18. http://www.who.int/classifications/icf

19. Cieza A, Geyh S, Chatterji S, et al. ICF linking rules: an update based on lessons learned. J Rehabil Med 2005;37:212-18.

20. Sprangers MA, Schwartz CE. Integrating response shift into health-related quality of life research: a theoretical model. Soc Sci Med 1999;48:1507-15.

21. Ubel PA, Loewenstein G, Jepson C. Whose quality of life? A commentary exploring discrepancies between health state evaluations of patients and the general public. Qual Life Res 2003;12:599-607.

22. Schwartz CE, Bode $\mathrm{R}$, Repucci $\mathrm{N}$, et al. The clinical significance of adaptation to changing health: a meta-analysis of response shift. Qual Life Res 2006;15:1533-50.

23. Janssen V, de Gucht V, van Exel $\mathrm{H}$, et al. Changes in illness perceptions and quality of life during participation in cardiac rehabilitation. Int J Behav Med 2013;20:582-89. 